\title{
Effect of Depth and Distance of the Borehole from the Septic Tank on the Physico-Chemical Quality of Water
}

\author{
Chove Lucy Mlipano \\ Sokoine University of Agriculture (SUA), Department of Food Technology, Nutrition \\ and Consumer Sciences, P. O. Box 3006, Morogoro, Tanzania \\ E-mail: lucychove@suanet.ac.tz; lucychove@yahoo.co.uk \\ Mongi Richard \\ Sokoine University of Agriculture (SUA), Department of Food Technology, Nutrition \\ and Consumer Sciences, P. O. Box 3006, Morogoro, Tanzania \\ E-mail: richard.mongi@gmail.com
}

Chenge Lawrence

Tanzania Bureau of Standards, P. O. Box 9524, Dar es Salaam, Tanzania

E-mail: rence85@gmail.com

Received: July 9, 2017 Accepted: December 26, 2017 Published: December 28, 2017

doi:10.5296/jfs.v7i1.12187 URL: https://doi.org/10.5296/jfs.v7i1.12187

\begin{abstract}
A study to examine the effect of depth and distance of the boreholes from the septic tank on physico-chemical parameters of the borehole water consumed in Dar Es Salaam, Tanzania was conducted. Samples were collected from 48 boreholes in Ilala, Kinondoni and Temeke districts and subjected to pH, B.O.D (Biological Oxygen Demand), total hardness, copper and lead analyses in relation to safety and quality levels set by WHO and TBS. Analysis by R-statistics indicated that $\mathrm{pH}$ and B.O.D significantly $(\mathrm{p}<0.05)$ decreased as the depth of borehole increased, whereas total hardness was significantly $(\mathrm{p}<0.05)$ higher in very deep boreholes than the other heights. Total hardness and $\mathrm{pH}$ were not significantly $(\mathrm{p}>0.05)$ affected by distance between septic tank and borehole and the B.O.D levels were significantly higher in the borehole water situated near the septic tank than those which were
\end{abstract}




\section{Macrothink}

far. Based on the physico-chemical characteristics of water, $25 \%$ of the samples did not comply with WHO and TBS specification limits while 75\% complied, most of which had shallow depths and were situated near the septic tank. It may thus be concluded that both the distance and the depth between septic tank and borehole influenced physico-chemical characteristics of water.

Keywords: B.O.D, Copper, Lead, pH, Total hardness

\section{Introduction}

Water is important for the existence of any forms of life (Khadsan \& Mangesh, 2003). There are a lot of guidelines, standards and regulations on drinking water quality that can offer public health protection (WHO, 2011). Drinking water is defined as potable water intended for human consumption (TBS, 2008). Safe water is important for human health and sustainable development (Sungsitthisawad \& Pitaksanurat, 2013). In many developing countries, citizens' access to reliable and safe water is a challenge (Kapongola et al., 2014). Groundwater is commonly alternative water resources in areas where surface water is not accessible (Sungsitthisawad \& Pitaksanurat, 2013). Ground water constitutes 97\% of global fresh water (Bharti et al., 2011) whose quantity, quality, accessibility and recharge depend mostly on geology, geomorphology, land use and levels of precipitation (Elisante \& Muzuka, 2015).

There are many factors that have to be considered when accessing the quality and safety of ground water as the drinking water. The water quality and safety indicator include the testing for total coliforms, faecal coliforms (E. Coli), inorganic contaminants, organoleptic (appearance, taste and odor) salinity, hardness, natural and artificially organic pollution and $\mathrm{pH}$ (TBS, 2008). The quality of ground water is the result of the processes and reactions that act on the water and varies from one place to another depending on the depth of the water table (Abong'o et al., 2017; Mohan et al., 2014). Groundwater can be contaminated by chemicals as well as microorganisms (Bharti et al., 2011). Furthermore groundwater resources in coastal areas like Dar Es Salaam are always in danger of contamination by sea water intrusion (Mtoni et al., 2012).

Generally, groundwater becomes purer with increase in depth (Ojo et al., 2012). Boreholes in Tanzania are classified as shallow $(0-30 \mathrm{~m})$, medium $(31-50 \mathrm{~m})$, deep (51-80 m), and very deep (>80 m) (Kashaigili, 2012; Baumann et al., 2005). It has been reported by Likambo (2014) that the further the distance from the borehole from the potential source of pollution, the more difficult it will be to become contaminated. In Tanzania, there is limited information on the physico-chemical qualities of groundwater based on their depth and distance to the septic tank

\section{Materials and Methods}

\subsection{Study Area}

This study was carried out at in three districts of Dar Es Salaam region namely Kinondoni (including Ubungo), Ilala and Temeke (including Kigamboni). 


\section{Al Macrothink}

\subsection{Materials}

Samples of borehole water from the three districts of Dar Es Salaam were used. Analytical grade reagents and chemicals, apparatus and laboratory equipment were obtained from TBS (Tanzania Bureau Of Standards) and WDMI (Water Development and Management Institute) Laboratories. Tape measure was purchased from a supplier in Dar Es Salaam.

\subsection{Study Design}

Randomized Complete Block Design was used in the study, where depth of the borehole (at 4 levels) and distance from the septic tank (at two levels) were the principal factors. The effects of these factors on physico-chemical quality of water were assessed. The mathematical model is as depicted in Equation below 1.

$$
Y i j=\mu+\alpha i+\beta j+\varepsilon i j
$$

Where $\mu$ is overall mean, $\alpha i$ is the effect of treatment $i$ (depth of the borehole), $\beta j$ is effect of block $j$ (distance to septic tank) and $\varepsilon i j$ random error

\subsection{Sampling Plan and Data Collection}

Purposive sampling plan was used to collect samples from selected boreholes in the three districts of Dar Es Salaam. A total of 48 samples were collected. Samples of two liters of water were collected after sterilizing the water tap/nozzle using cotton wool soaked in $70 \%$ $(\mathrm{v} / \mathrm{v})$ ethanol and allowed water to run for 1 minute. Sampling was carried out from November 2016 - January 2017. Samples were collected in the transparent clean and sterile $500 \mathrm{mls}$ glass bottles (Duran, made in Germany) but samples for B.O.D analysis were collected in the amber glass bottles. Samples were stored in an insulated ice box and transported to the TBS and WDMI laboratories for further analysis.

\subsection{Physico-chemical Laboratory Analyses}

\section{$2.5 .1 \mathrm{pH}$}

It was determined according to ISO 10523:2008. Results were expressed and recorded in two decimal places.

\subsubsection{Total Hardness}

It was analyzed according to ISO 6059:1984 procedures. Results were expressed in milligram per liter of $\mathrm{CaCO}_{3}$.

\subsubsection{Biochemical Oxygen Demand (B.O.D)}

The Biochemical Oxygen Demand of the water samples for 5 days at $20{ }^{\circ} \mathrm{C}$ were determined according to ISO 5815-2:2003. The samples were equilibrated at $20{ }^{\circ} \mathrm{C}$ followed by determination of the dissolved oxygen concentration at day 0 and day 5 . Results were expressed in milligram per liter.

\subsubsection{Metal contaminants Copper $(\mathrm{Cu})$ and Lead $(\mathrm{Pb})$}

Copper $(\mathrm{Cu})$ and Lead $(\mathrm{Pb})$ were analyzed according to ISO 11885:2007. Results were expressed in milligram per liter.

\subsection{Statistical Data Analysis}

Data was analyzed using R- statistical package software version 3.3.0. Analysis of Variance (ANOVA) was carried out to determine the significant difference between the main factors. Means were separated using Tukey's Honest at $\mathrm{p}<0.05$. 


\section{Macrothink}

\section{Results and Discussion}

\subsection{The Effect of Depth of the Borehole On Physico-chemical Characteristics of the Water}

\subsubsection{Effect of Depth on $\mathrm{pH}$ of Water}

The $\mathrm{pH}$ of the water samples collected was as shown on Figure 1. There were significant differences $(\mathrm{p}<0.05)$ in $\mathrm{pH}$ between the various levels of depths in all the districts. Shallow and medium boreholes had a higher $\mathrm{pH}$ than the deep and very deep boreholes which were significantly different $(\mathrm{p}<0.05)$ at all depth levels for all the districts.

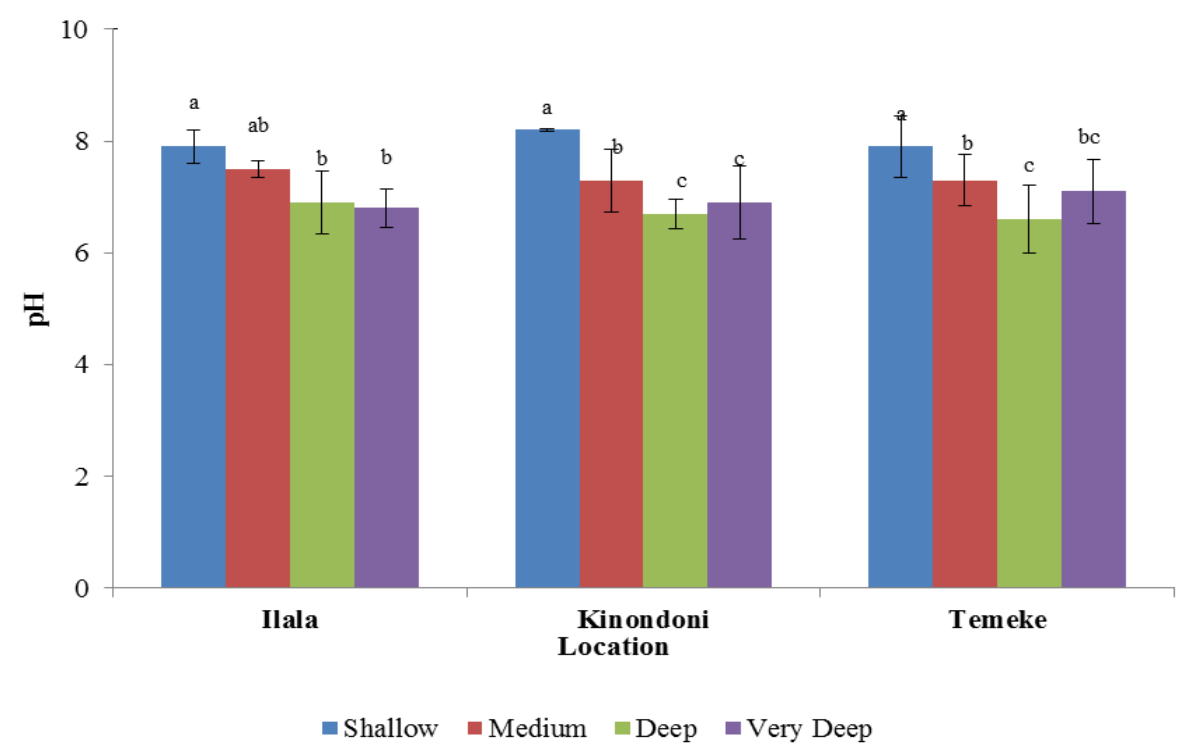

Figure 1. Effect of depth on $\mathrm{pH}$. Bars are expressed as mean $\pm \mathrm{SD}(\mathrm{n}=48)$. Bar with different letters are significantly different at $\mathrm{p}<0.05$

These findings confirm that the $\mathrm{pH}$ of water from shallow and medium borehole was significantly higher compared to deep and very deep wells. Furthermore all the shallow and medium boreholes water $\mathrm{pH}$ fall with the recommended $\mathrm{pH}$ of drinking water is $6.5-9.2$ for Tanzania (TBS, 2008) and 6.5-8.5 (WHO, 2011). It was further revealed that $25 \%$ and $16.7 \%$ of the deep and very deep boreholes water respectively, did not comply with the WHO and Tanzania standards as they showed a slightly acidic $\mathrm{pH}$. The lower the $\mathrm{pH}$ of water, the more likely it to be corrosive (WHO, 2011). The slightly higher $\mathrm{pH}$ of the shallow and medium boreholes water which most of them were around or near the coastal area of Dar Es Salaam were attributed by reasons that most of them derived from the limestone aquifer (Mtoni et al., 2012). The limestone was found along a narrow coastal belt (Mato, 2002). In additional, Witte (2012) found higher $\mathrm{pH}$ value for boreholes water that were closer to the coast and indicated that it was possibly due to the presence of the coral reefs. When calcite in the reef dissolves, calcium and carbonate are set free.

Furthermore Mtoni et al. (2012) reported that bicarbonate was the dominant anion in the upper aquifer while in the lower aquifer chloride was the dominant anion. Aina and Oshunrinade (2016) confirmed that alkalinity of water was due to the presence of carbonates, bicarbonates, and hydroxides. 


\section{Macrothink}

\subsubsection{Effect of Depth on Biochemical Oxygen Demand (B. O. D)}

Although all samples fall within the maximum B.O.D $(6.0 \mathrm{mg} / \mathrm{L})$ established by TBS (TBS, 2008), there were significant differences $(p<0.05)$ in B. O. D. between the depth categories within the districts (Figure 2). Shallow boreholes had significantly $(\mathrm{p}<0.05)$ highest B.O.D compared to the rest of the depth categories (Figure 2). Significantly similar lowest values in deep and very deep boreholes were observed in Ilala, Kinondoni and Temeke. The B.O.D significantly $(\mathrm{p}<0.05)$ decreased as depth of the borehole increased. Also the results showed that the Temeke boreholes water contained the highest amount of B.O.D followed by Ilala while in Kinondoni had least as shown on Figure 2.

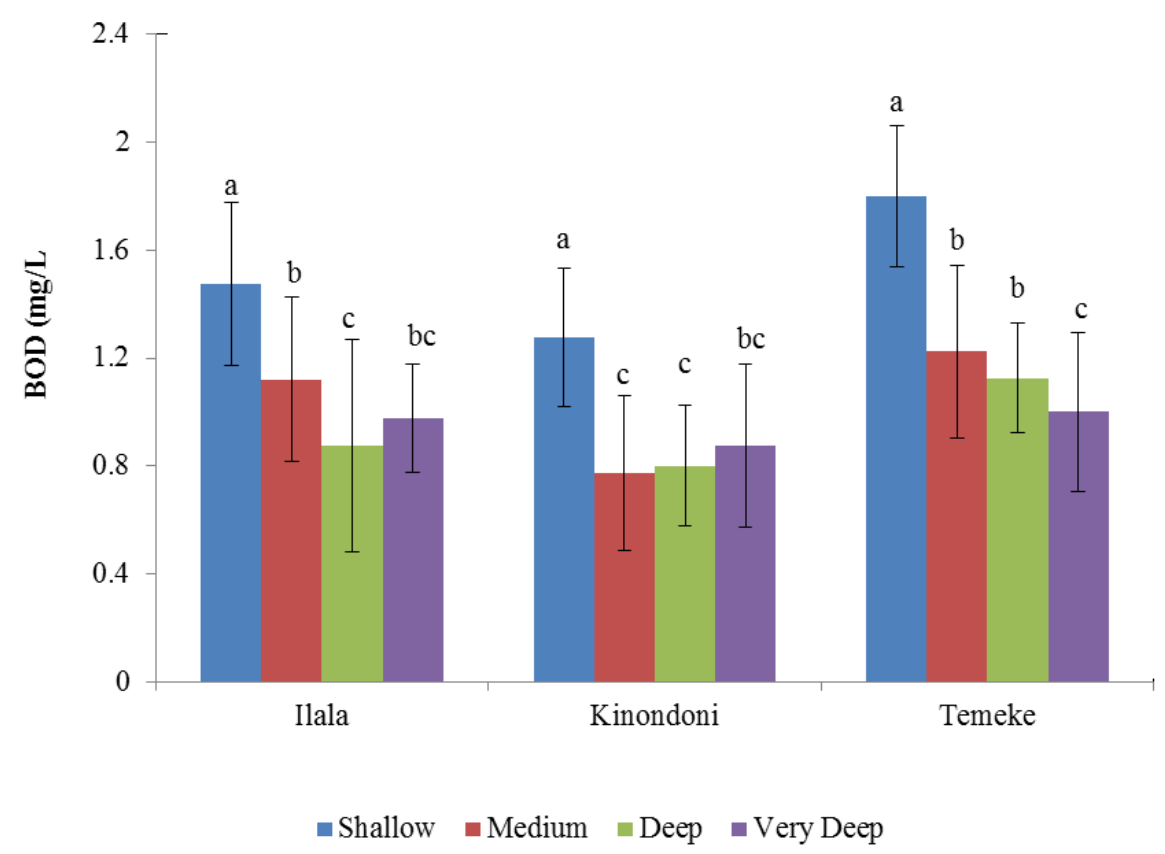

Figure 2. Effect of depth on B.O.D. Bars are expressed as mean \pm SD ( $n=48)$. Bar with different letters are significantly different at $\mathrm{p}<0.05$

The results confirmed that generally B.O.D of the borehole water decreased as the depth of the well increased. Ojo et al. (2012) revealed that groundwater becomes purer with increase in depth. The higher level of B.O.D indicates groundwater pollution (Ojo et al., 2012). The higher level B.O.D on the shallow boreholes compared to deep boreholes indicated that shallow boreholes water contained more organic matter compared to deep boreholes. Sindelar (2015) reported that as water moved through soil, it was continuously being cleaned. Therefore as water moved to the deeper aquifers, it was further cleaned compared to that which moved on the upper aquifers.

\subsubsection{Effect of Depth on Total Hardness of Water}

Figure 3 showed that there were significant differences $(\mathrm{p}<0.05)$ in total hardness within and between the districts at each level of depth. Very deep boreholes had the significantly highest levels of water hardness compared to shallow boreholes. The highest levels were found in very deep borehole of Kinondoni and Temeke as shown in Figure 3. The lowest levels were 


\section{Mll Mascrothink}

found in the shallow boreholes in Ilala, Kinondoni and Temeke respectively. On average the Kinondoni boreholes had the highest levels total hardness followed by Temeke and lastly Ilala.

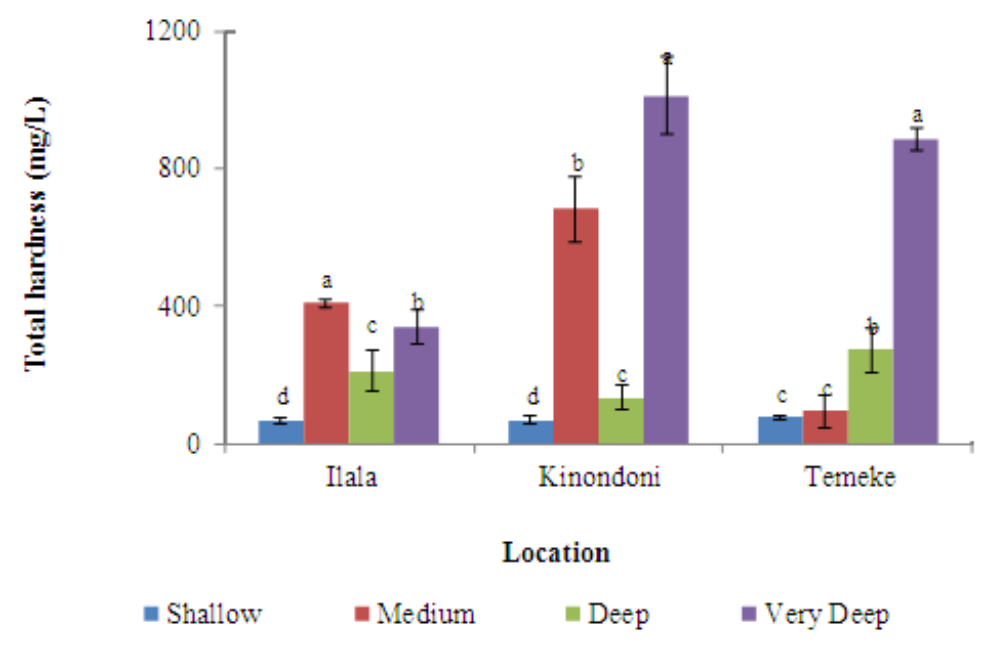

Figure 3. Effect of depth on total hardness. Bars are expressed as mean $\pm \operatorname{SD}(n=48)$. Bar with different letters are significantly different at $\mathrm{p}<0.05$

Groundwater is normally harder than surface water because of its high solubilizing potentials from rocks containing gypsum, calcite and dolomite (Ojo et al., 2012). Despite of other negative effect, minerals dissolved in water have a benefits of contribute to the taste of drinking water (WHO, 2011). According to the TBS specification the maximum hardness in drinking water is $600 \mathrm{mg} / \mathrm{l}$ (TBS, 2008). About 16.7\% of all samples did not comply whereby $62.5 \%$ were from very deep boreholes. Aina and Oshunrinade (2016) reported that water hardness was caused by natural accumulation of salts from contact with soil and geological formation. Therefore the longer groundwater takes to move through the sediments, the more mineralized it becomes. Thus, groundwater increased in mineral content as it moved along through the pores and fracture openings in rocks. This caused deeper waters to be highly mineralized.

\subsubsection{Effect of Depth on Metal Contaminants (Lead and Copper)}

The levels of the copper and lead were detected in all districts (Figure 4). There were significant differences $(\mathrm{p}<0.05)$ in copper within and between the districts with shallow, medium, deep and very deep. All the samples met the maximum limits established by WHO and TBS. The highest copper values were found in medium depth of Ilala and very deep depth of Temeke while the least levels were identified in very deep of Ilala followed by very deep of Kinondoni (Figure 4). Lead was detected only in deep and very deep boreholes whereby in Ilala and Temeke were found only in deep boreholes while in Kinondoni were found only in very deep boreholes (Figure 4). 


\section{Macrothink}
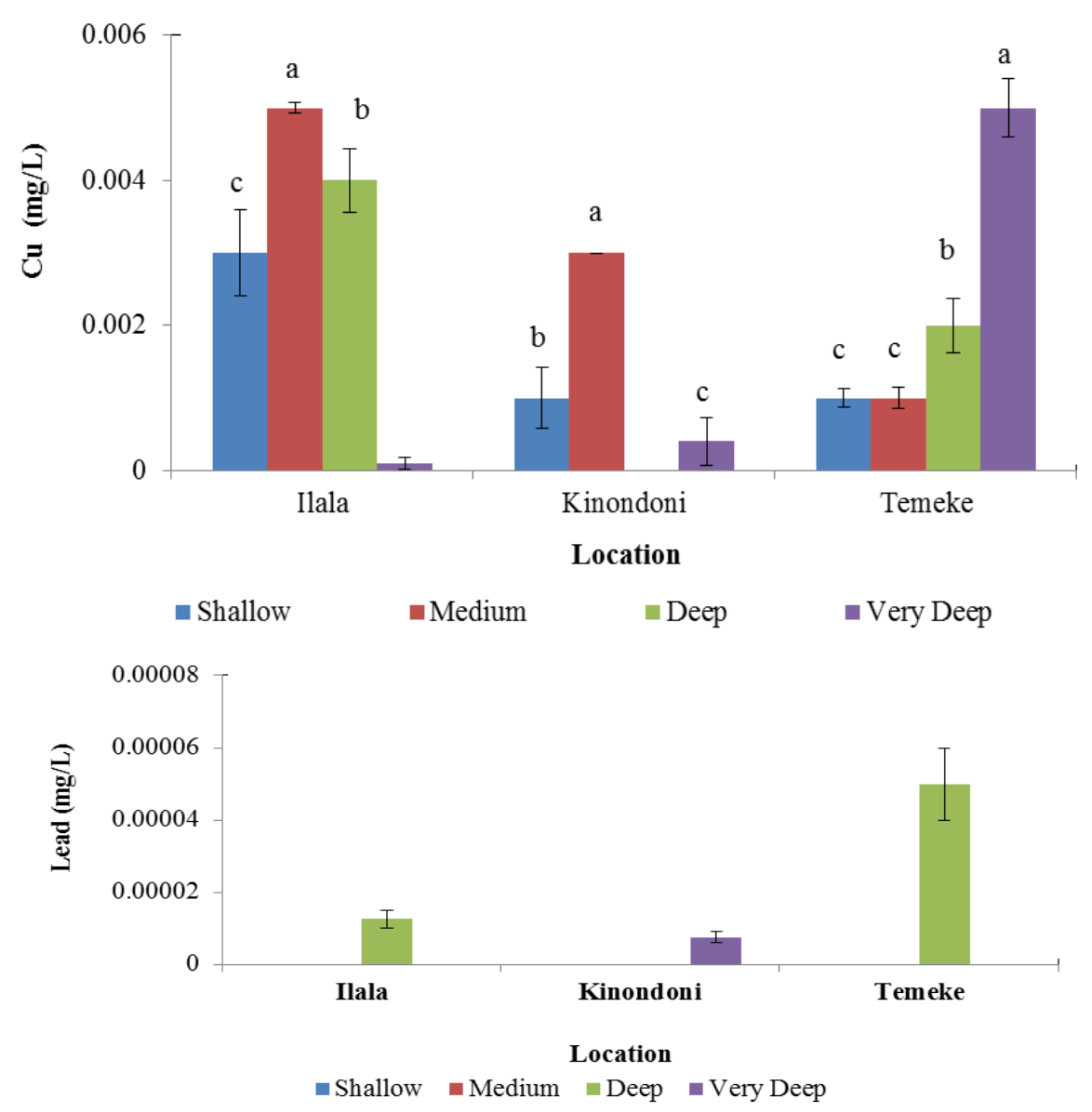

Figure 4. Effect of depth on copper and lead. Bars are expressed as mean $\pm \mathrm{SD}(\mathrm{n}=48)$. Bar with different letters are significantly different at $\mathrm{p}<0.05$

Contamination of metals from pipe fitting was rare regardless of the water acidic $\mathrm{pH}$ because of changes in technology of using metal pipes to PEX pipes (Crosslinked Polyethylene). PEX pipes are being commonly used nowadays as domestic water pipes. WHO (2011) realized that plumbing materials, pipes, fittings and coatings can result in elevated heavy metal. Shallow and medium boreholes showed less amount of lead compared to deep and very deep boreholes as it was identified by WHO (2011) that waters with high $\mathrm{pH}$, calcium and alkalinity are less corrosive to the metal parts of water distribution systems. Furthermore WHO (2011) acknowledged that high levels of dissolved oxygen have been shown to accelerate copper corrosion from copper pipes. Moreover ground water depth and quality varies from place to place as it affected the quality of water as it moved in various kinds of rocks, soils and pick up natural contaminants (Peter-Ikechukwu et al., 2015).

3.1.5 Compliance of Physico-chemical Characteristic of Water to TBS and WHO Limits in Relation to Depth

Table 1 shows distribution of boreholes' depth according to compliance on physico-chemical specifications as set by WHO and TBS. Despite the observed variations, water samples from different depth levels were within the maximum allowable limits for BOD and metal contaminants (Copper and Lead) set by WHO and TBS. 
Table 1. Distribution of boreholes' depth according to their compliance to WHO and TBS standards on physico-chemical specifications

\begin{tabular}{lllllllll}
\hline Depth & Pass (\%) & \multicolumn{9}{l}{ Parameter Fail } & & \multicolumn{2}{c}{ Total (\%) } \\
& & pH & B.O.D & Hardness & Combination & Sub Total & \\
\hline Shallow & $12(100)$ & - & - & - & - & $0(0)$ & $12(100)$ \\
Medium & $9(75)$ & - & - & 3 & - & $3(25)$ & $12(100)$ \\
Deep & $9(75)$ & 3 & - & - & - & $3(25)$ & $12(100)$ \\
V. Deep & $6(50)$ & 1 & - & 4 & 1 & $6(50)$ & $12(100)$ \\
\hline
\end{tabular}

This indicates that $16.7 \%$ of the samples total hardness were above $600 \mathrm{mg} / \mathrm{L}$ established by TBS (2008) and $10.4 \%$ of all samples did not comply with neither WHO nor TBS, whose $\mathrm{pH}$ should range between $\mathrm{pH} 6.5-8.5$ and between 6.5 - 9.2 respectively (WHO, 2011; TBS, 2008).

3.2 The Effect of Distance from the Septic Tank to the Borehole on Physico-chemical Characteristics of the Water

\subsubsection{The Effect of Distance between the Septic and Borehole on $\mathrm{pH}$}

Figure 5 shows that there were no significant differences $(\mathrm{p}<0.05)$ in $\mathrm{pH}$ resulting from the effect of the distance between septic tank and borehole.

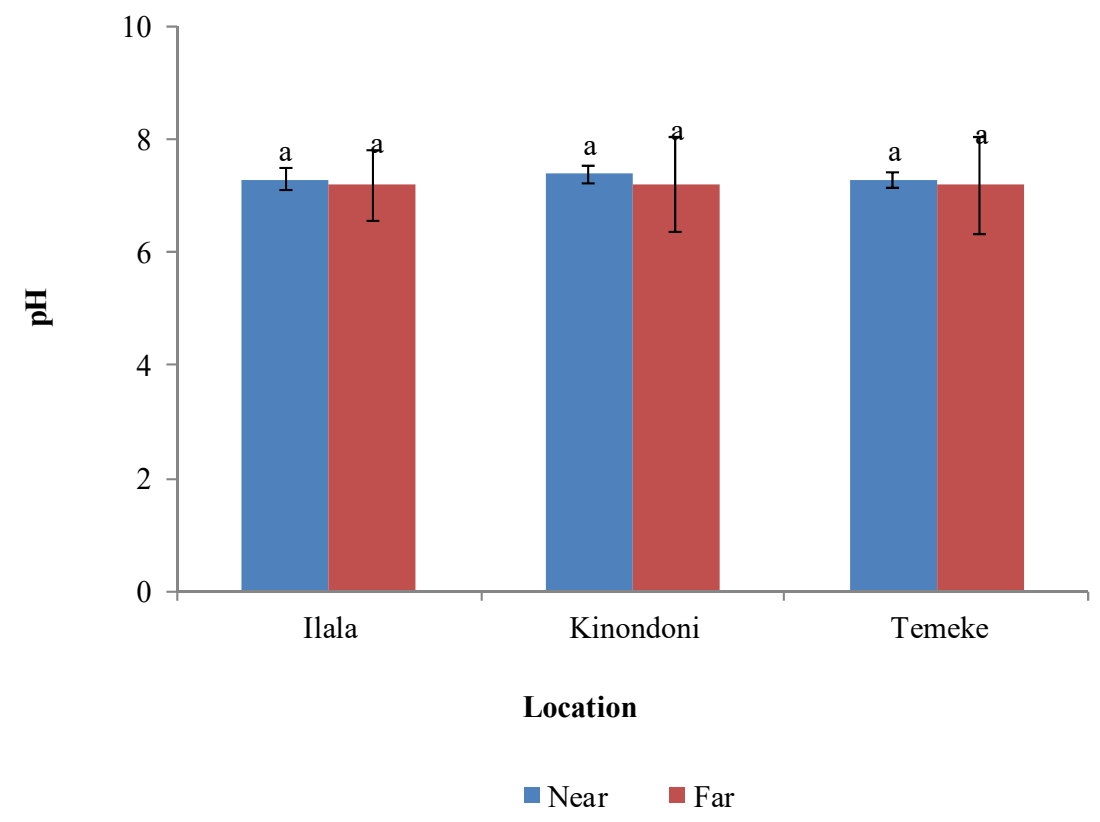

Figure 5. Effect of distance between borehole and septic tank in relation to $\mathrm{pH}$. Bars are expressed as mean $\pm \mathrm{SD}(\mathrm{n}=48)$. Bar with different letters are significantly different at $\mathrm{p}<0.05$

Fubara-Manuel and Jumbo (2014) reported that the effect of the distance from the septic tanks to boreholes is noticeable where the adjoining geological formation is fissured. Earth fissures are associated with basin subsidence that accompanies extensive ground water 
mining. During torrential rains they erode rapidly presenting a substantial hazard to people and infrastructure. Moreover, fissures provide a ready conduit to deliver runoff and contaminated waters to basin aquifers (AGS, 2011). Fissures have destroyed pipelines, roads, canals, and even homes. Earth fissures create an easy place for groundwater to become contaminated (AGS, 2011) which may result in $\mathrm{pH}$ changes. However, Fubara-Manuel and Jumbo (2014) found no significant difference in $\mathrm{pH}$ in relation to the distance between the septic tank and the borehole. Eze and Eze (2015) confirmed that there were slight variation in $\mathrm{pH}$ but variations did not show any correlations with the distance of the borehole from septic tank.

\subsubsection{The Effect of Distance between the Septic and Borehole on B.O.D}

There were significant differences $(p<0.05)$ in Biochemical Oxygen Demand (B.O.D) of the boreholes that were constructed near $(<15 \mathrm{~m})$ and far $(>15 \mathrm{~m})$ from the septic tank. The B.O.D significantly decreased $(\mathrm{p}<0.05)$ as the distance between the borehole and septic tank increased irrespective of the districts (Figure 6). The B.O.D of the boreholes water was significantly higher in the boreholes that were nearer the septic tank than those which were further and vice-versa. Although the highest B.O.D were found in boreholes that were near the septic tank in Ilala followed by Temeke and final Kinondoni, no significant differences in B.O.D. levels were found between the three districts (Figure. 6).

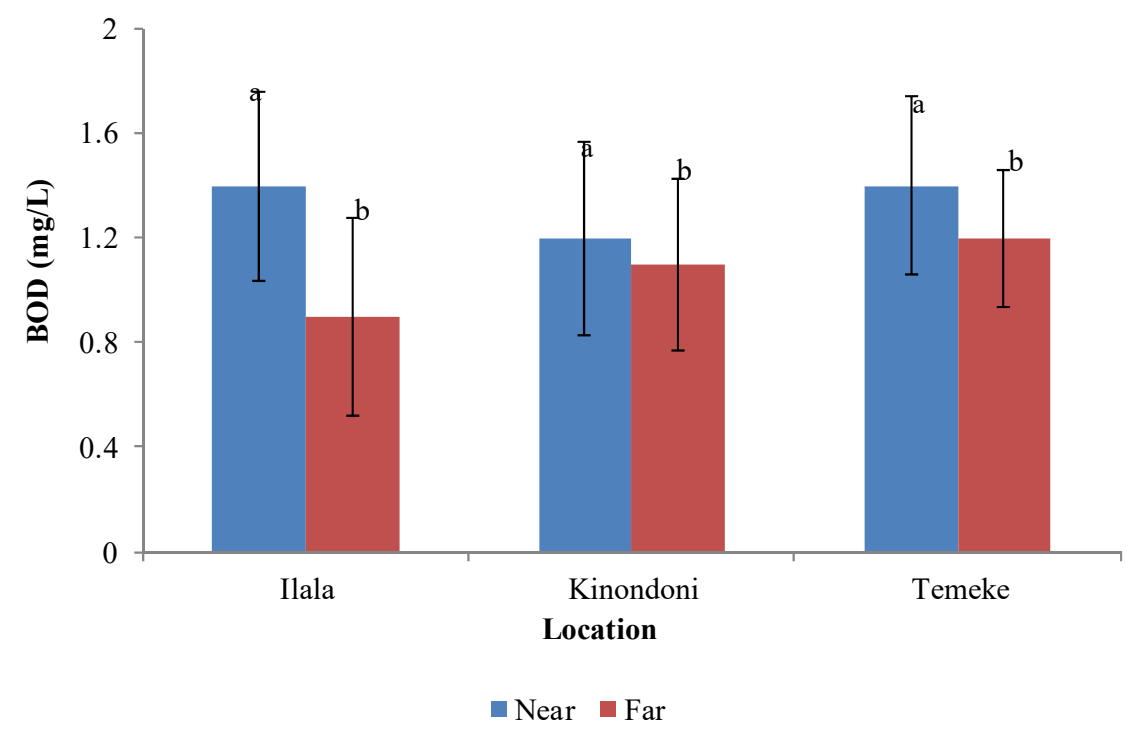

Figure 6. Effect of distance between borehole and septic tank in relation to B.O.D. Bars are expressed as mean $\pm \mathrm{SD}(\mathrm{n}=48)$. Bar with different letters are significantly different at $\mathrm{p}<0.05$

The B.O.D results of all samples ranged from 0.9 to $1.4 \mathrm{mg} / \mathrm{L}$ which complied with the TBS limit of $6 \mathrm{mg} / \mathrm{L}$ as a maximum (TBS, 2008). There were higher organic matter in boreholes water which were closer to the septic tank than those far from the septic tanks. The higher organic matter in the water was contributed by effluent from the septic tank. In view of the above McQuillan (2004) confirmed that domestic water utilization adds organic matter 


\section{Macrothink

(typically measured as biochemical oxygen demand, BOD) to sewage. Therefore the higher organic matter in borehole water near the septic tank werecontributed by sewage in the tank.

\subsubsection{The Effect of Distance between the Septic and Borehole on Total Hardness}

There were significant differences $(p<0.05)$ in total water hardness of boreholes located at distances near $(<15 \mathrm{~m})$ and far $(>15 \mathrm{~m})$ from the septic tank in Ilala and Kinondoni districts (Figure 7). However, no significant differences $(\mathrm{p}>0.05)$ in total water hardness between the two distances in Temeke district. In Ilala district, the farther the distance between borehole and the septic tank, the higher the levels of total water hardness. The situation of the Kinondoni district however, was the opposite (Figure 7).

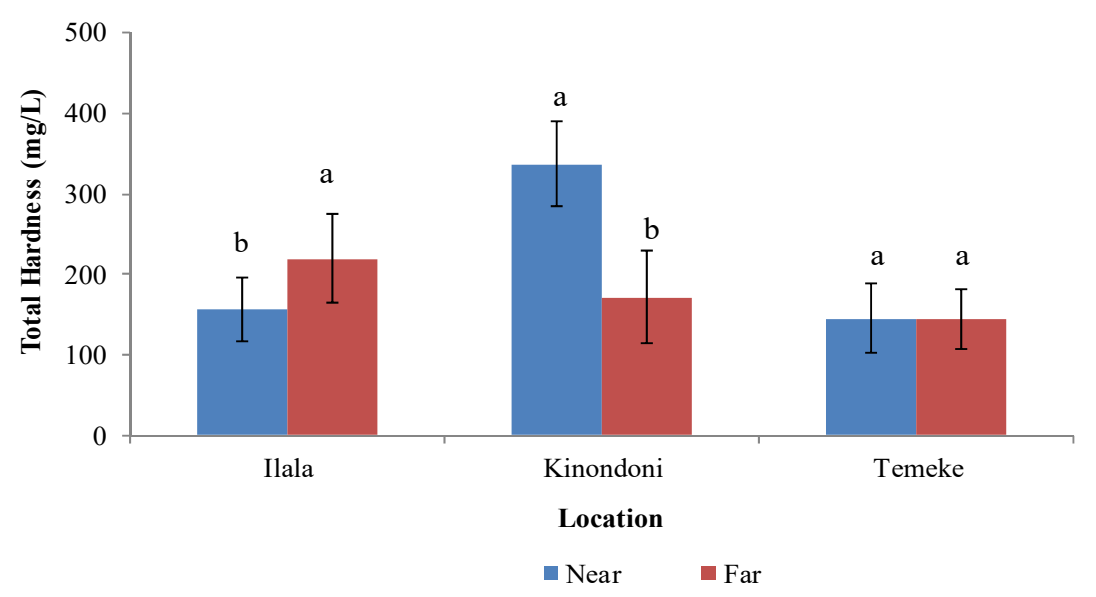

Figure 7. Effect of distance between borehole and septic tank in relation to water hardness. Bars are expressed as mean $\pm \mathrm{SD}(\mathrm{n}=48)$. Bar with different letters are significantly different at $\mathrm{p}<0.05$

In view of the above Figure, since there was no clear pattern to explain the differences in the three districts, there are probably other factors which contributed to water hardness more than distance between septic tank and the boreholes. Palamuleni and Akoth (2015) mentioned other factors which contributed to groundwater minerals composition included seasonal changes of the water depending on the types of soils, rocks and surfaces through which it moved. As groundwater passes through the sediments, metals dissolved and these would be found in high concentrations in the water. Hardness was caused by calcium and magnesium and it had no health effect but it affected the quality of the water (WHO, 2011). According to Waskom and Bauder (2009) in order to protect the boreholes from septic tank regardless the distance between them, boreholes should be uphill from septic systems in relation to the soil type, the hydrologeology and age of the borehole.

This meant that even if the distance between the septic tank and boreholes was long, the boreholes might still be contaminated if it is located downhill from the septic tank. It was reported that groundwater moved to the direction of the lowest hydraulic head (where groundwater was released into streams, lakes) from a high hydraulic head which was a 


\section{Macrothink}

recharge area (Witte, 2012). Waskom and Bauder (2009) reported that total dissolved solids (TDS) in groundwater may vary depending on well recharge characteristics and TDS measures the total amount of dissolved minerals, metals, salts and may contain undesirable amounts of calcium, magnesium, sulfate, chloride, or other salts. Peter-Ikechukwu et al. (2015) concluded that distance between septic tank and borehole had little or no correlation with TDS and total hardness.

3.2.4 The Effect of Distance between the Septic and Borehole on Metal Contaminants (Lead and Copper)

Distance from the septic tank showed significant differences $(p<0.05)$ in copper levels of boreholes waterwhich were located near and far from the septic tank in all districts (Figure 8). The levels of copper increased significantly $(p<0.05)$ as the distance between the borehole and septic tank increased. The significantly high values of copper were found in the borehole water which located far away from the septic in the Ilala and Temeke districts. The significantly low levels were found in the boreholes water located near to the septic tank in Kinondoni followed by Temeke and finally Ilala districts (Figure 8). Lead was much lower than copper. Lead was detected only in the boreholes which were near to the septic tank in Temeke and Kinondoni districts whereas it was detected in borehole far away from the septic tank in Ilala district (Figure 8).

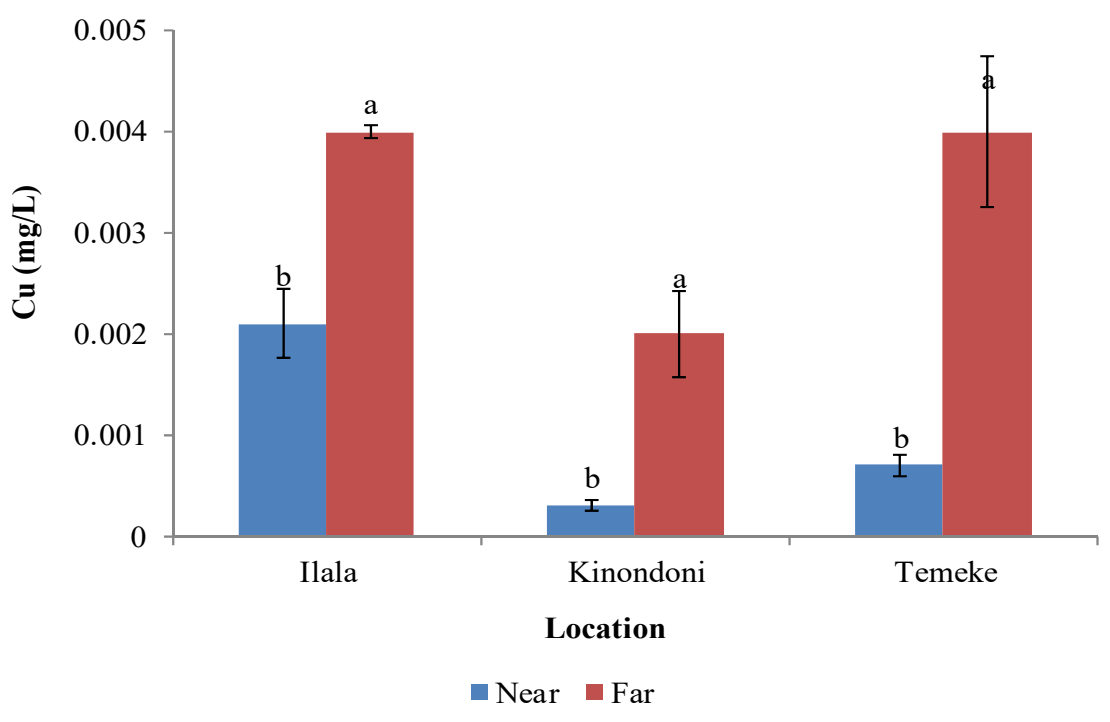




\section{Macrothink}

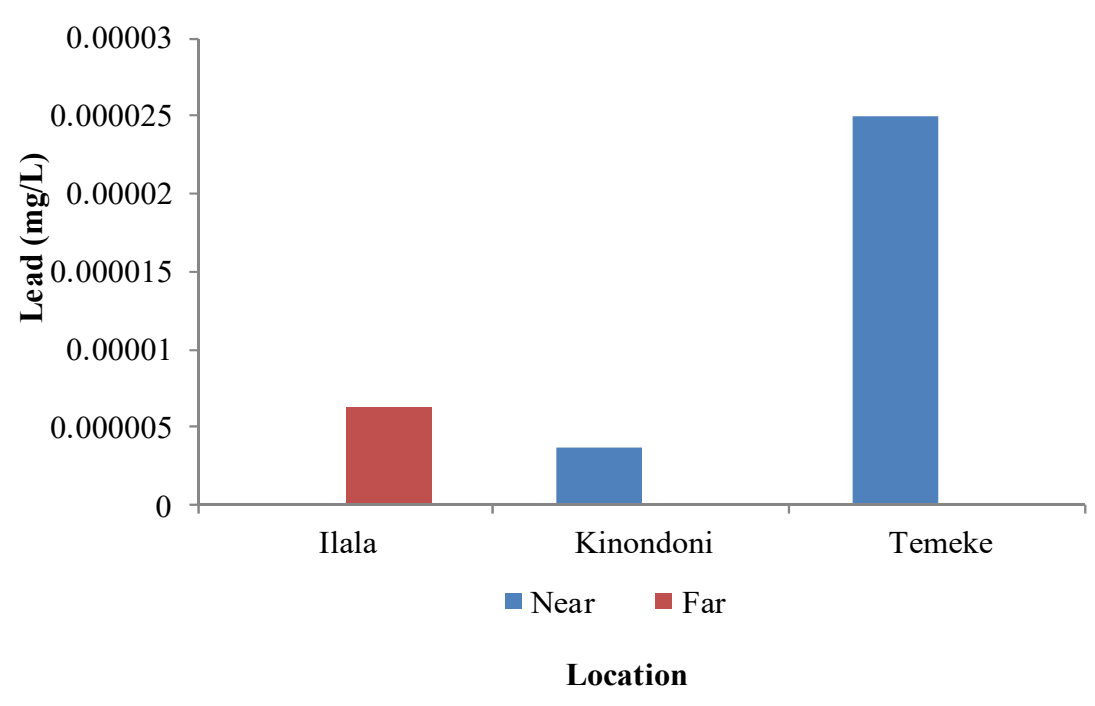

Figure 8. Effect of distance between borehole and septic tank on copper and lead. Bars are expressed as mean $\pm \mathrm{SD}(\mathrm{n}=48)$. Bar with different letters are significantly different at $\mathrm{p}<0.05$

Copper and lead levels were low and complied with the maximum limits established by TBS and WHO. Mkude (2015) explained that the levels of copper in boreholes of Dar Es Salaamwere very minimal and could be due to the intrusion of industrial and domestic wastes. Palamuleni and Akoth (2015) also explained that naturally occurring metals present in the rocks and sediments may be dissolved in the water and later be found in water. Furthermore lead contamination to ground water may be the result of entry from industrial effluents, old plumbing, household sewages, agricultural run-off containing phosphate fertilizers, human and animal excreta (Mkude, 2015). The $\mathrm{pH}$ values of neutral and slightly alkaline decreases the availability of the metals ions in water as the metal would remain attached in substrate and complexes, therefore significantly lower levels of metals contaminants could result from the neutral $\mathrm{pH}$ of the borehole water samples from both near and far away from the septic tank (Kihampa, 2013).

3.2.5 Compliance of Borehole Water to WHO and TBS on Physic-chemical Parameters based on Distance between Borehole and Septic Tank

The effect of distance between borehole and septic tank on physico-chemical limits compliance set by WHO and TBS are as shown on Table 2 . About $79.2 \%$ of water samples drawn from boreholes that were near the septic tank complied with the WHO and TBS specification and $70.8 \%$ were from samples further from the septic tank. The rest did not comply, neither with WHO nor TBS standards (Table 2). Although in general, most samples complied with the standards and a few did not, it is important to monitor the quality of water so as to ensure the safety of consumers. Based on the findings of this study, it is recommended that all boreholes water should be treated regardless of the distance from potential pollutants. In addition, before drilling a borehole, drillers should take into consideration of all the factors that will affect the water quality such depth, distance to the potential pollutants, groundwater flow direction and soil structure. 
Table 2. Distribution of boreholes' distance to septic tank according to their compliance on WHO and Tanzania physico-chemical specifications

\begin{tabular}{llllllll}
\hline Distance & Pass (\%) & \multicolumn{3}{c}{ Parameter Failed } & & \multicolumn{2}{c}{ Total (\%) } \\
& & pH & B.O.D & Hardness & Combination & Sub Total & \\
\hline Near & $19(79.2)$ & 5 & - & - & - & $5(20.8)$ & $24(100)$ \\
Far & $17(70.8)$ & 4 & - & 2 & 1 & $7(29.2)$ & $24(100)$ \\
\hline
\end{tabular}

\section{Conclusion}

This study showed that both the depth of the borehole and the distance from the borehole to the septic tank have effect on the physico-chemical quality of the water. Both the $\mathrm{pH}$ and B.O.D decreased significantly as the depth of the boreholes increased, while for very deep boreholes water had significantly higher levels of total hardness compared to shallow boreholes. The distance between the septic tank and boreholes had no effect on $\mathrm{pH}$ and total hardness, while the B.O.D decreased significantly as distance between the septic tanks and boreholes increased. Generally, regardless of the depth of the boreholes and distance to the septic tank, the levels of copper and lead detected were very low. Thus, except for $\mathrm{pH}$ and total hardness of some samples, all physico-chemical parameters were within the limit stipulated by TBS and WHO.

\section{References}

Abong'o, D. H. A., Mbugua, H., \& Onyatta, J. O. (2017). The effect of septic tanks sewage disposal system distances on borehole water quality in Ongata Rongai, Kajiado County, Kenya. European International Journal of Science and Technology, 6(3), 2-9.

Aina, A. T., \& Oshunrinade, O. O. (2016). Comparison of water quality from boreholes and hand-dug wells around and within the University of Lagos, Lagos, Nigeria. Journal of Research in Environmental Studies, 3, 93-100.

Arizona Geological Survey. (2011). Earth Fissure Centre http://www.azgs.az.gov/EFC.shtml visited on 25th November, 2017 at 9.30am

Bharti, D., Sayyad, I. A., Gaikwad, G. G., Taikar, D. R., \& Dhore, J. (2011). Physico-chemical characteristics of Bore well water quality in Nagpur region (South zone). Journal of Chemical and Pharmaceutical Research, 3(2), 922-927.

Elisante, E., \& Muzuka, A. N. N. (2015). Occurrence of Nitrate in Tanzanian Groundwater Aquifers: A Review.Springer Publisher, New York, USA.

Eze, C. L., \& Eze, E. M. (2015). Investigation of possible groundwater contamination from septic system sitting in Port Harcourt, Nigeria. Journal of Natural Sciences Research, 5(10), 83-86.

Fubara-Manuel, I., \& Jumbo, R. B. (2014). The effect of septic tank locations on borehole water quality in Port Harcourt, Nigeria.International Journal of Engineering and Technology, 4(5), 236-241. 
Kapongola, N., Martineza, J., Wesselinka, A., Lungob, J. H., \& Georgiadoua Y. (2014). Accessing water services in Dar es Salaam: Are we counting whatcounts? Journal of Habitat International, 44, 358-366. https://doi.org/10.1016/j.habitatint.2014.07.003

Kashaigili, J. J. (2012). Report on assessment of groundwater availability and its current and potential use and impacts in Tanzania. In:Groundwater Availability and Use in Sub-Saharan Africa: A Review of 15 Countries. (Edited by Pavelic, P., Giordano, M., Keraita, B., Ramesh, V. and Rao T.), International Water Management Institute, Colombo, Sri Lanka. pp. 195-216. Khadsan, R. E., \& Mangesh, V. K. (2003). Drinking water quality analysis of some bore-wells water of Chikhli Town, Maharashtra. Journal of Industrial Pollution Control, 20(1), 31-36.

Kihampa, C. (2013). Heavy metal contamination in water and sediment downstream of municipal wastewater treatment plants, Dar es Salaam, Tanzania. International Journal of Environmental Sciences, 3(5), 1407-1413.

Likambo, W. (2014). Assessment of borehole water quality and consumption in yei county South Sudan. Dissertation for Award of MSc Degree at Makerere University, Kampala, Uganda.

Mato, R. R. A. M. (2002). Groundwater Pollution in Urban Dar es Salaam, Tanzania: Assessing Vulnerability and Protection Priorities.Eindhoven Technische Universiteit, Eindhoven.

McQuillan, D. (2004). Ground-water quality impacts from on-site septic systems.In: Proceedings National Onsite Wastewater Recycling Association, $13^{\text {th }}$ Annual Conference. 7-10 November, 2004 Albuquerque, New Mexico. pp. 1-11.

Mkude, I. T. (2015). Comparative analysis of heavy metals from groundwater sources situated in Keko and Kigogo residential areas, Dares Salaam. Journal of Water Resources and Ocean Science, 4(1), 1-5. https://doi.org/10.11648/j.wros.20150401.11

Mohan, K. C., Suresh, J., \& Venkateswarlu, P. (2014). Physio-chemical analysis of bore-well water of Kurnool environs, Andhra Pradesh. Journal of Chemical and Pharmaceutical Research, 6(9), 77-80.

Mtoni, Y., Mjemah, I. C., Msindai, K., Camp, M. V., \& Walraevens, K. (2012). Saltwater intrusion in the quaternary aquifer of the Dar Es Salaamregion, Tanzania. Journal of Geologica Belgica, 15(2), 16-25.

Ojo, O. I., Otieno, F. A. O., \& Ochieng, G. M. (2012). Groundwater: Characteristics, qualities, pollutions and treatments: An overview. Journal of Water Resources and Environmental Engineering, 4(6), 162-170.

Palamuleni, L., \& Akoth, M. (2015). Physico-Chemical and Microbial Analysis of Selected Borehole Water in Mahikeng, South Africa. International Journal of Environmental Research and Public, 12, 8619-8630. https://doi.org/10.3390/ijerph120808619

Peter-Ikechukwu, A., Omeire, G. C., Okafor, D. C., Eluchie, C., Odimegwu N. E., Nze, S. N., Anagwu, F. I., \& Okeke, K. C. (2015). Assessment of the quality of borehole water sample in federal housing estate and sites and services areas of Owerri, Imo State, Nigeria. Journal of Food Science and Quality Management, 42, 5-12. 


\section{Macrothink}

Journal of Food Studies

ISSN 2166-1073 2018, Vol. 7, No. 1

Sindelar, M. (2015). Soils Clean and Capture Water. Soil Science Society of America, Madison, Wisconsin, USA.

Sungsitthisawad, W., \& Pitaksanurat, S. (2013). Groundwater quality index for water supply production. Journal of EnvironmentAsia, 6(2), 18-23.

Tanzania Bureau of Standards. (2008). Tanzania Standard on Drinking (Portable) Water TZS 789. Tanzania Bureau of Standards, Dar es Salaam, Tanzania.

Waskom, R. M., \& Bauder, T. A. (2009). Report on Protecting Your Private Well. Water Institute Colorado State University, Colorado.

WHO. (2011). Guidelines for Drinking-water Quality. (4th Edition), World Health Organization, Geneva, Switzerland.

Witte, I. D. (2012). Characterization of the status of Dar Es Salaamaquifer in view of salt-water intrusion and nitrate contamination. Dissertation for Award of MSc Degree in Geology at Ghent University.

\section{Copyright Disclaimer}

Copyright for this article is retained by the author(s), with first publication rights granted to the journal.

This is an open-access article distributed under the terms and conditions of the Creative Commons Attribution license (http://creativecommons.org/licenses/by/3.0/). 